\title{
Caso: gestão de equipamentos de proteção individual - EPI no Porto de Ponta da Madeira
}

Case: personal protective equipment management - PPE in the Port of Ponta da Madeira

\section{Caso: gestión de equipos de protección individual - EPI en el Puerto de Punta de Madera}

\author{
Adiene Ferezin Custodio \\ Graduada em Engenharia de Alimentos \\ FABIO ARRUDA \\ Graduado e Mestre em Administração
}

\begin{abstract}
Resumo O Terminal Marítimo Ponta da Madeira - TMPM possuía várias iniciativas relacionadas à gestão de Equipamentos de Proteção Individual - EPI, porém todas atuando de forma descentralizada. Diante disso, foi identificada a necessidade de gerenciar todas as ações em conjunto, visando simplificar o processo e otimizar ações direcionadas. A boa prática apresentada neste caso mostra a introdução, em 2014, de sistema eletrônico em postos de coleta e entrega desses materiais com objetivo de melhorar a sistemática de entrega, uso e fiscalização de EPI, bem como, a implantação de um programa de simplificação, o EPI Inteligente, tendo em vista o conforto e o bem-estar, sem comprometer a saúde e a segurança dos empregados. Palavras-chave: EPI. Boas práticas. Terminal Marítimo da Ponta da Madeira - TMPM.
\end{abstract}

Abstract The Maritime Terminal of Ponta da Madeira had many initiatives related to Personal Protective Equipment - PPE management, but all of them operating in a decentralized way. In this sense, it was identified the need to implement a system of centralized management in order to simplify this process and to optimize dedicated actions. The good practice analysed in this case approach the implementation in 2014 of an electronic system to manage collection and delivery locals dedicated to improve the delivery, use and controlling PPE's process, as well, to implement a simplified program, the Intelligent EPI, to promote the well-being and comfort of the employees without compromising their health and safety.

Keywords: PPE. Good practices. Maritime Terminal of Ponta da Madeira - TMPM. 
Resumen Lo Terminal Marítima Ponta da Madeira - TMPM poseía varias iniciativas relacionadas a la gestión de Equipos de Protección Individual - EPI, pero todas actuando de forma descentralizada. Por lo tanto, se identificó la necesidad de gestionar todas las acciones en conjunto, buscando simplificar el proceso y optimizar acciones dirigidas. La buena práctica presentada en este caso muestra la introducción en 2014 de sistema electrónico en puestos de recolección y entrega de esos materiales con el objetivo de mejorar la sistemática de entrega, uso y fiscalización de EPI, así como la implantación de un programa de simplificación, el EPI Inteligente, teniendo en cuenta el confort y el bienestar, sin comprometer la salud y la seguridad de los empleados.

Palabras clave: EPI. Buenas practicas. Terminal Marítimo de la Punta de Madeira TMPM.

\section{INTRODUÇÃO}

A gestão de Equipamentos de Proteção Individual - EPI - no TMPM compreende a determinação, recomendação, fornecimento, registro de entrega e devolução, uso, orientação e treinamento, guarda e conservação, substituição, higienização, manutenção e descarte de Equipamentos de Proteção Individual - EPI. Todo EPI adquirido pela Vale possui Certificado de Aprovação - CA - emitido pelo Ministério do Trabalho, conforme Norma Regulamentadora n. 6 e Portaria b. 452, de 20 de novembro de 2014 do MTPS.

Os EPIs são fornecidos gratuitamente aos empregados e são adequados aos riscos de suas atividades, conforme especificação técnica de cada EPI. Os profissionais de Segurança do Trabalho são os responsáveis em determinar o tipo de EPI específico à função do empregado, com base nos riscos mapeados nas atividades de cada processo, ouvindo a CIPA (Comissão Interna de Prevenção de Acidentes) e trabalhadores usuários. O perfeito estado de conservação e utilização é garantido por meio de trocas periódicas e inspeções (que cada empregado realiza individualmente).

Para melhorar toda a gestão da entrega e controle dos EPIs consumidos no TMPM, implantou-se e está em operação, atualmente, um sistema eletrônico chamado SIGEPI - Sistema de Gestão de EPI.

\section{O SISTEMA DE GESTÃO DE EPI - SIGEPI}

Desde 2014, ano de sua implantação, o SIGEPI trouxe inúmeros benefícios para o TMPM. Foram instalados postos de entregas de EPI em locais de maior fluxo de empregados, denominados de Postos de EPI Express, com funcionamento 24 horas.

A ferramenta de gestão foi implementada junto ao Kanban, termo de origem japonesa, que significa literalmente cartão ou sinalização e se apresenta como sistema variante do Just in Time, criado na Toyota em 1960, para permitir um controle detalhado de produção com informações sobre quando, quanto e o que produzir. Essa sistemática foi adotada, e permitiu padronizar a gestão de materiais, controle de níveis de estoque e gestão visual dos itens disponíveis e de maior rotatividade nos Postos de EPI Express. 

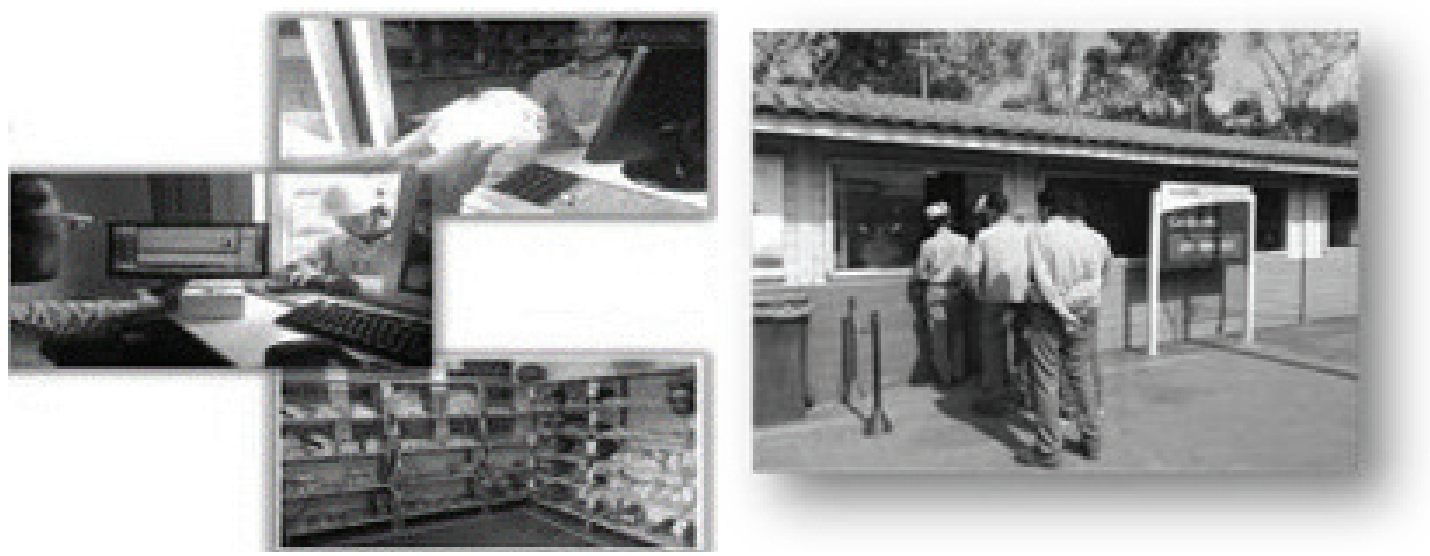

Figura 1 - Posto de EPI Express - TMPM.

Alguns dos benefícios com a criação dos Postos de EPI dessa forma foram: a manutenção de estoque centralizado com níveis saudáveis e parametrizados dos itens; número reduzido de empregados envolvidos no processo, desde o controle do estoque até a entrega do EPI para o empregado; ganhos de produtividade; confiabilidade; processo automatizado; visão imediata dos consumos por relatórios gerenciais. A Figura 2 apresenta o fluxo de materiais adotados nos Postos de EPI Express na Reposição de Materiais.

\begin{tabular}{|c|c|c|c|c|}
\hline $\begin{array}{l}\text { Armazém gera } \\
\text { relatórios dos itens } \\
\text { para reposiçãoe } \\
\text { emvia para Usuário } \\
\text { requisitar }\end{array}$ & $\begin{array}{l}\text { Usuário emite } \\
\text { requisiçäodos } \\
\text { itens corforme } \\
\text { relatório de } \\
\text { reposiçăo erriado } \\
\text { pelo Arrmazém }\end{array}$ & $\begin{array}{l}\text { Fornecedor } \\
\text { homologado } \\
\text { separa materiase } \\
\text { entregaparao } \\
\text { Armazém }\end{array}$ & $\begin{array}{l}\text { Armazém } \\
\text { reabastece o } \\
\text { Posto de EPI } \\
\text { Express }\end{array}$ & $\begin{array}{l}\text { Operador do } \\
\text { Posto de EPI } \\
\text { Express registrao } \\
\text { recebimento dos } \\
\text { materiais }\end{array}$ \\
\hline
\end{tabular}

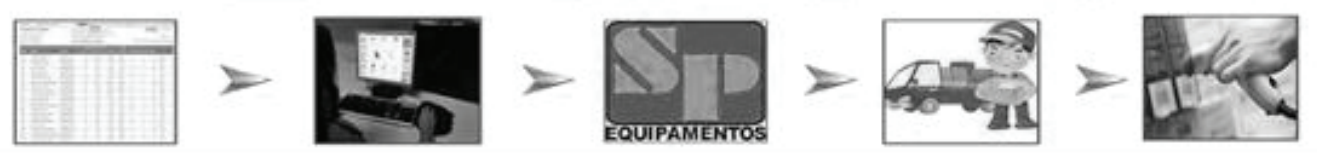

Figura 2 - Fluxo de Reposição de Materiais.

Antes da implantação do SIGEPI, um dos maiores problemas identificados eram as inúmeras fichas de EPI (de papel) arquivadas, que geravam um volume de armazenamento muito grande, dificultando, assim, a rastreabilidade das entregas e devoluções (baixa).

O gerenciamento e o controle dessas fichas, quando em transferências de empregados, ou mesmo nos casos de demissões, também eram muito prejudicados por extravios ou danos, o que dificultava a rastreabilidade dos EPIs entregues, além de gerar grande volume de armazenamento desse histórico, para empregados demitidos. Toda essa problemática afetava o desenvolvimento de defesas em casos de perícias trabalhistas recebidas pela empresa, tendo em vista que a maior parte desses processos exige a verificação da ficha de EPI do empregado. 
Com o SIGEPI nos Postos de EPI Express, o empregado faz a retirada do seu EPI toda vez que necessário, como já ocorria, no entanto, agora o recebimento é registrado pelo sistema por meio de equipamentos de leitura biométrica ou por inserção de senha individual do empregado, que é intransferível, garantindo segurança e idoneidade ao processo.

Além disso, a entrega fica atrelada à função e riscos associados ao empregado, permitindo um controle adequado sobre o equipamento que lhe é repassado. Os registros de entrega ficam armazenados no sistema, o que permite a consulta, toda vez que necessária, ao histórico do que foi recebido pelo empregado.

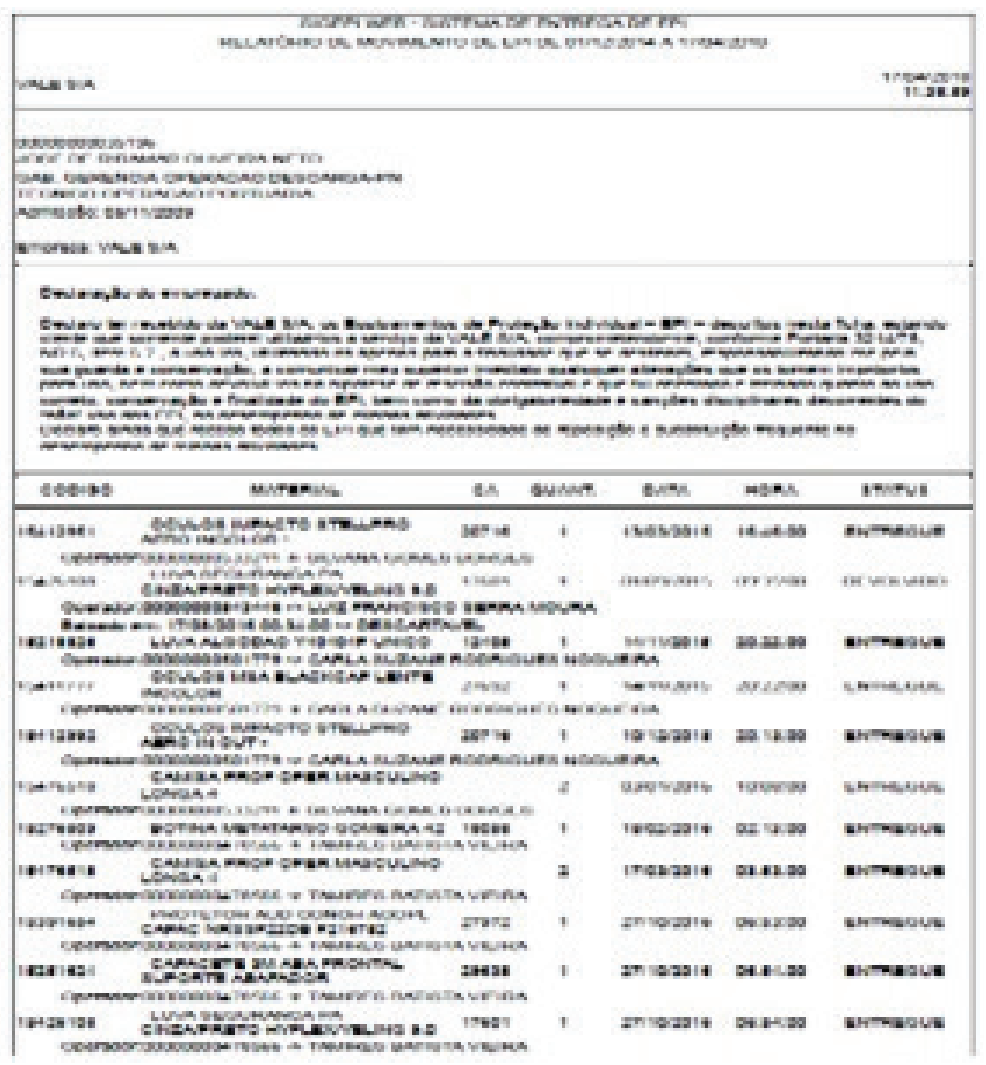

Figura 3 - Modelo de Ficha de EPI gerada pelo SIGEPI.

O SIGEPI também permite extrair a ficha individual de EPI de cada empregado, por períodos determinados, a partir do momento de seu cadastro no sistema eletrônico e, nesse primeiro momento, é gerado um Termo de Conhecimento e Responsabilidade, com as obrigatoriedades de utilização que, também o informam que a Vale utiliza um sistema eletrônico de gerenciamento de entrega/baixa de EPI. Com esse termo, o empregado assume total responsabilidade pelo uso da senha, não devendo em hipótese alguma fornecê-la para outra pessoa, sob pena de aplicação de sanções disciplinares. 
O sistema também fornece relatórios gerenciais para acompanhamento do consumo e periodicidade de trocas de EPI pelos empregados das áreas. Alguns dos ganhos foram verificados desde a sua implantação:

- O sistema garante o arquivamento das fichas de entrega de EPI de forma eletrônica, evitando com isso a geração de papel e a necessidade de espaço físico para sua guarda por, no mínimo, 20 anos.

- A assinatura do empregado é realizada por meio da biometria ou de senha pessoal.

- Permite a extração de relatórios de entrega e análise dos dados para gerenciamento.

- Auxilia a VALE nos processos trabalhistas relacionados à Segurança do Trabalho.

A Figura 4 mostra as telas do sistema eletrônico de EPI (SIGEPI) para a entrega de EPI, com o registro eletrônico da entrega por empregado mediante senha eletrônica ou biometria.
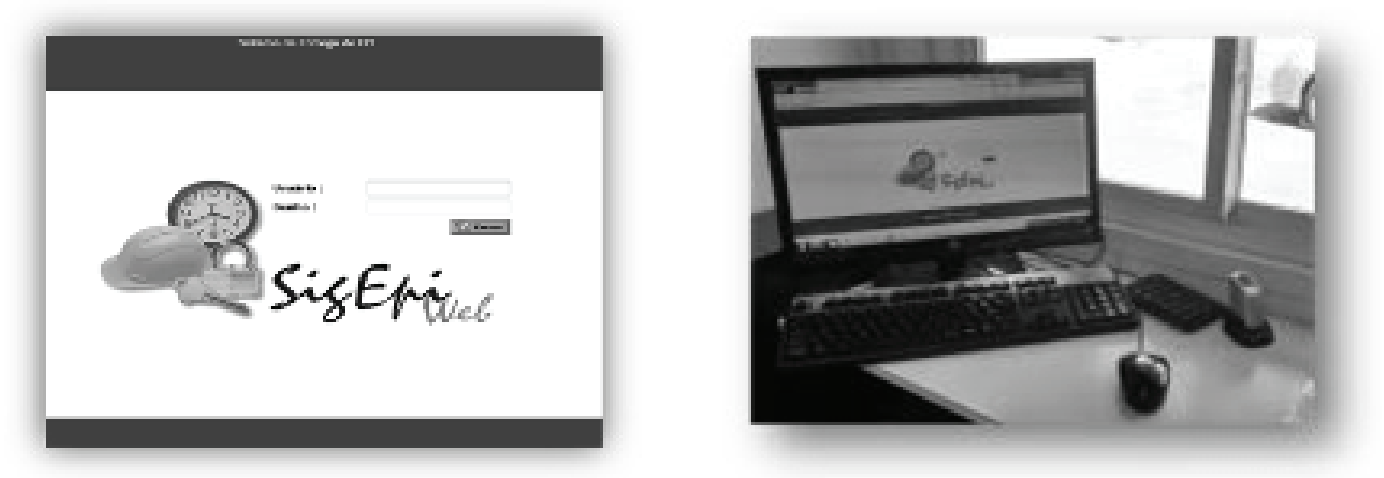

Figura 4 - SIGEPI: Sistema de Gerenciamento Eletrônico de EPI.

A Figura 5 mostra o Fluxo de atendimento do empregado no Posto de EPI Express.

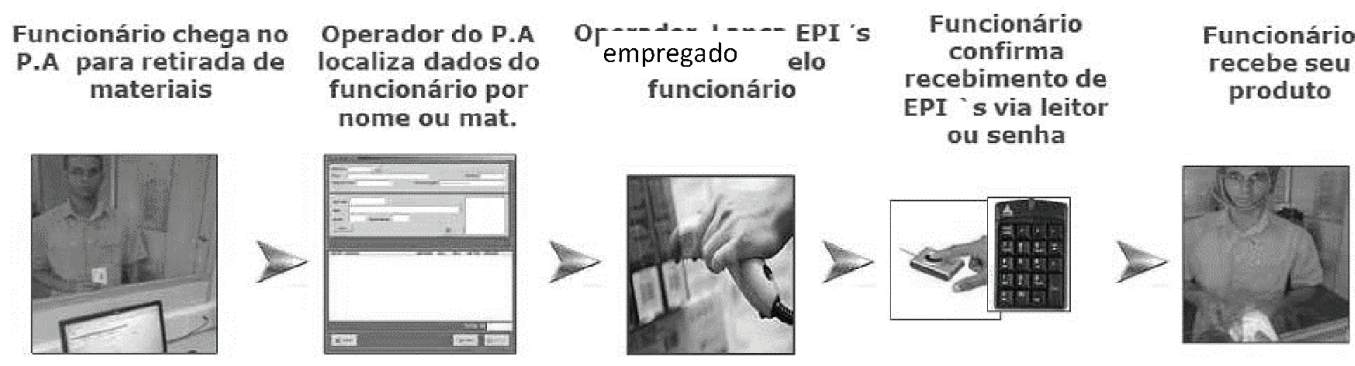

Figura 5 - Fluxo de Atendimento do Posto de EPI Express.

O gerenciamento realizado pelo SIGEPI também possibilitou a otimização de recursos, como o controle de entrega por cargo e vida útil de determinado EPI com maior segurança de fornecimento do EPI adequado para cada função e monitoramento de vida útil do equipamento de proteção. Como consequência, obteve-se a redução de custo pela substituição de EPI com o mesmo nível de proteção e, com o controle de periodicidade de troca, evitaram-se trocas desnecessárias do EPI pelo empregado, conforme ilustra a Figura 6. 


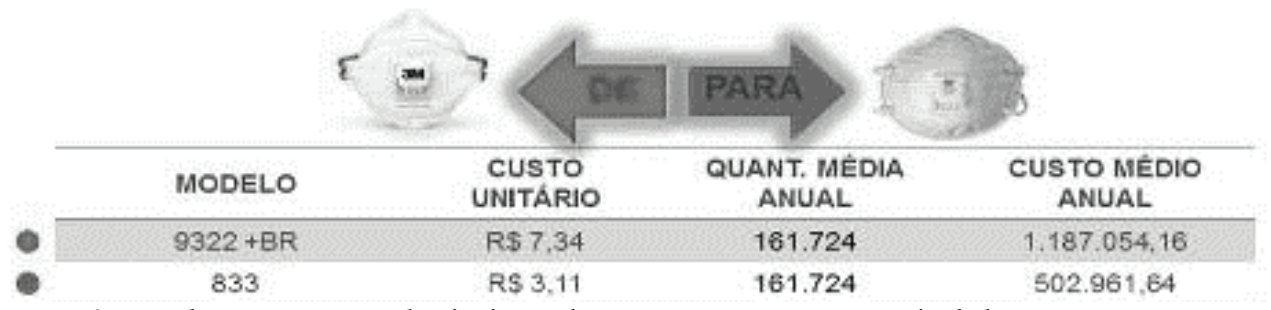

Figura 6 - Redução custo: substituição de EPI com o mesmo nível de proteção.

A Figura 7 mostra definições de periodicidade de troca de EPI, para a reposição dos itens pelos empregados.

\begin{tabular}{|c|c|c|}
\hline EPI & Descriçäo do EPI & Tempo mảximo de reposiçăo \\
\hline & Protetor auricular tipo plug & 30 dias \\
\hline & Protetor auricular tipo concha & $\begin{array}{l}01 \text { ano função operacional } \\
02 \text { anos função administrativa }\end{array}$ \\
\hline & Respirador semi-facial PFF2 e PFF3 & 7 dias \\
\hline 8 & Filtro químico para respiradores & 180 dias \\
\hline & Luva nitrilica/PVC contra agentes quimicos & 60 dias \\
\hline & Macacão impermeável contra agentes quimicos & 60 dias \\
\hline 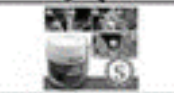 & $\begin{array}{l}\text { Creme de proteção contra óleos e graxas (Iuva } \\
\text { química) }\end{array}$ & 60 dias \\
\hline (E) & Creme bloqueador solar & 90 dias \\
\hline
\end{tabular}

Figura 7 - Exemplo de determinação de periodicidade de troca de EPI.

A Figura 8 demonstra como se dá o controle de estoque, funcionalidade do sistema eletrônico SIGEPI utilizada nos Postos de EPI Express. 


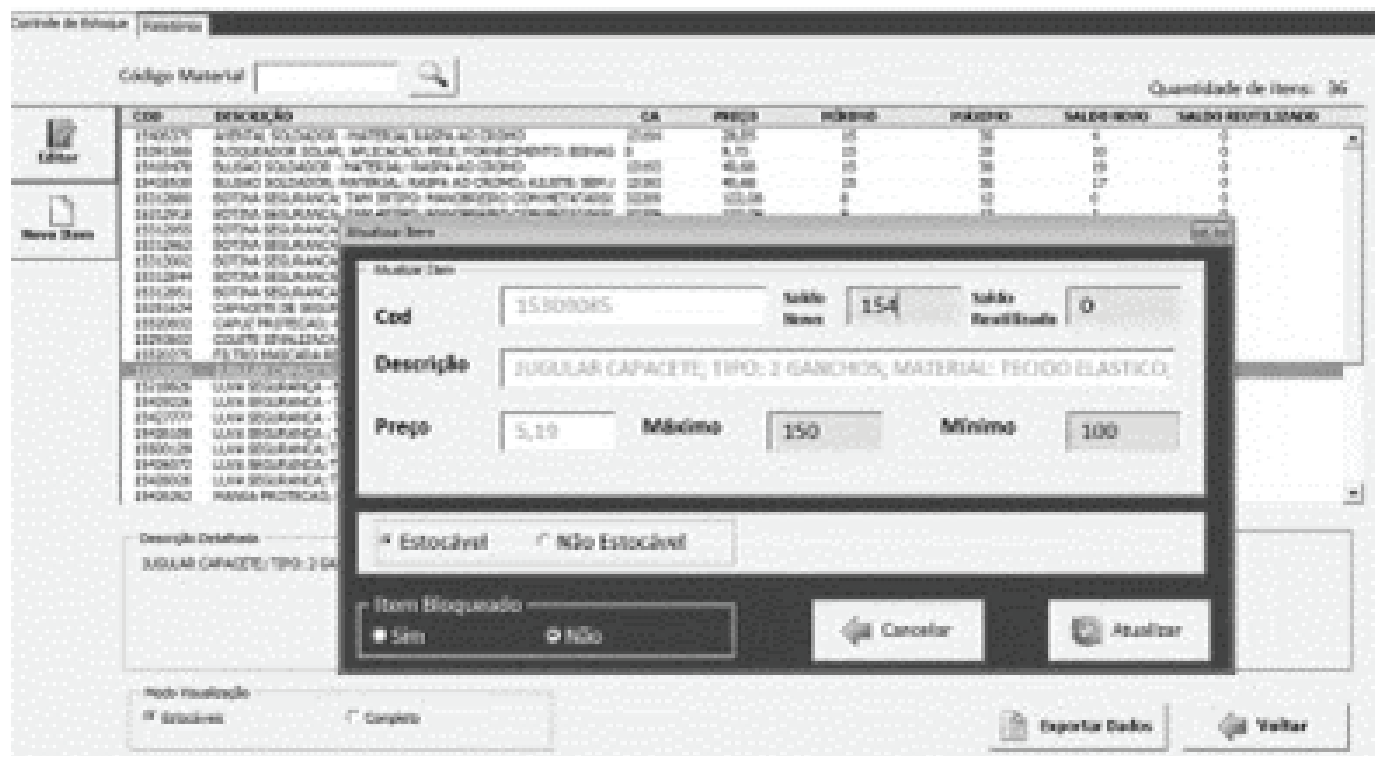

Figura 8 - SIGEPI: Tela de gerenciamento do controle de estoque.

Os gráficos estatísticos das Figuras 9 a 11 têm origem nos relatórios do SIGEPI e compõem relatórios gerenciais de movimentação de entregas de EPI dos consumos por funções, área e maiores quantidades retiradas, por período determinado.
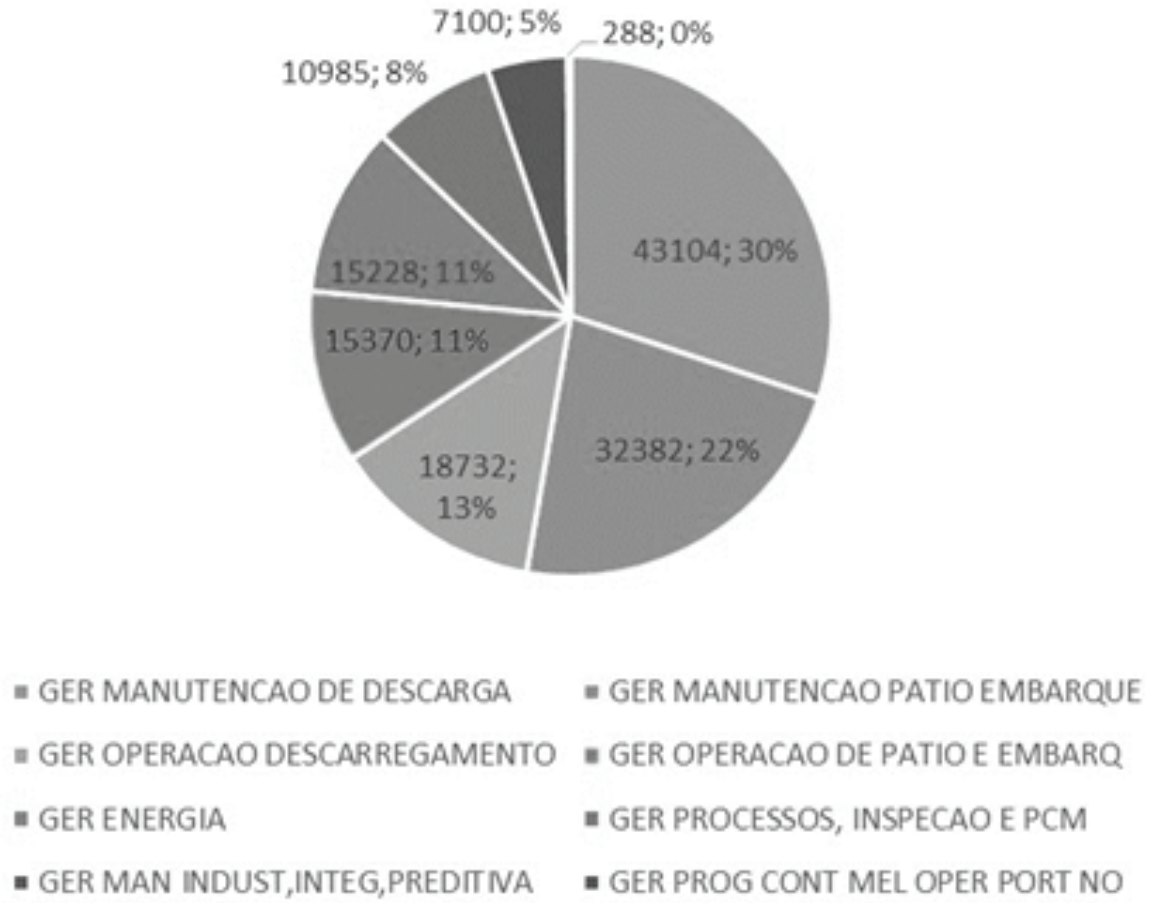

Figura 9 - SIGEPI: Gráfico da estatística de consumo de EPI por área (quantidade). 

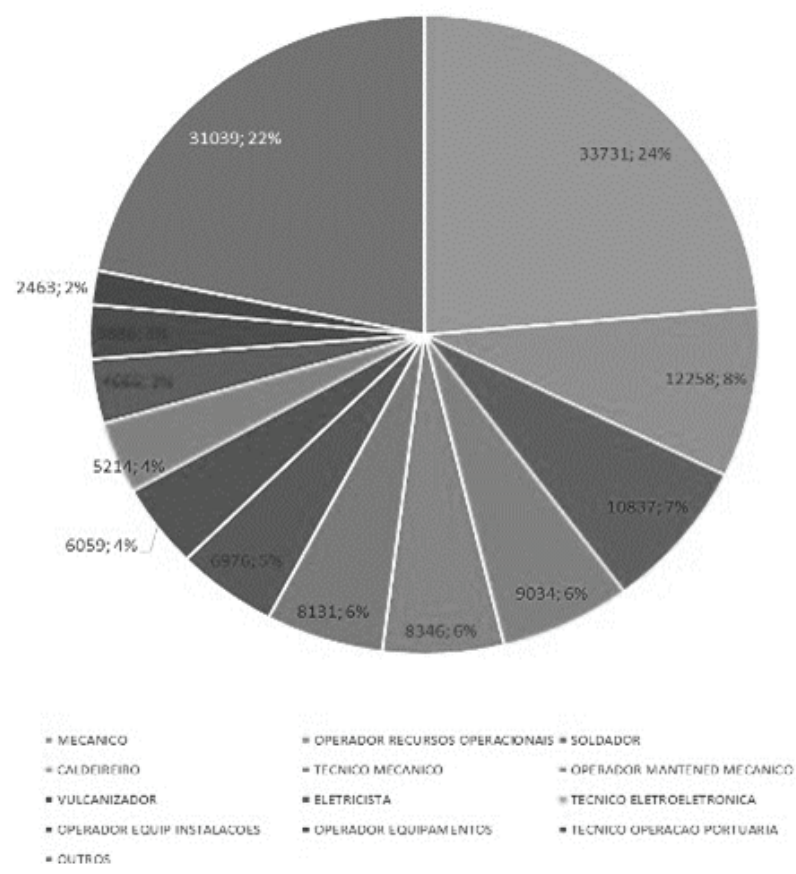

Figura 10 - SIGEPI: Gráfico da estatística de EPIs retirados por função (quantidade).

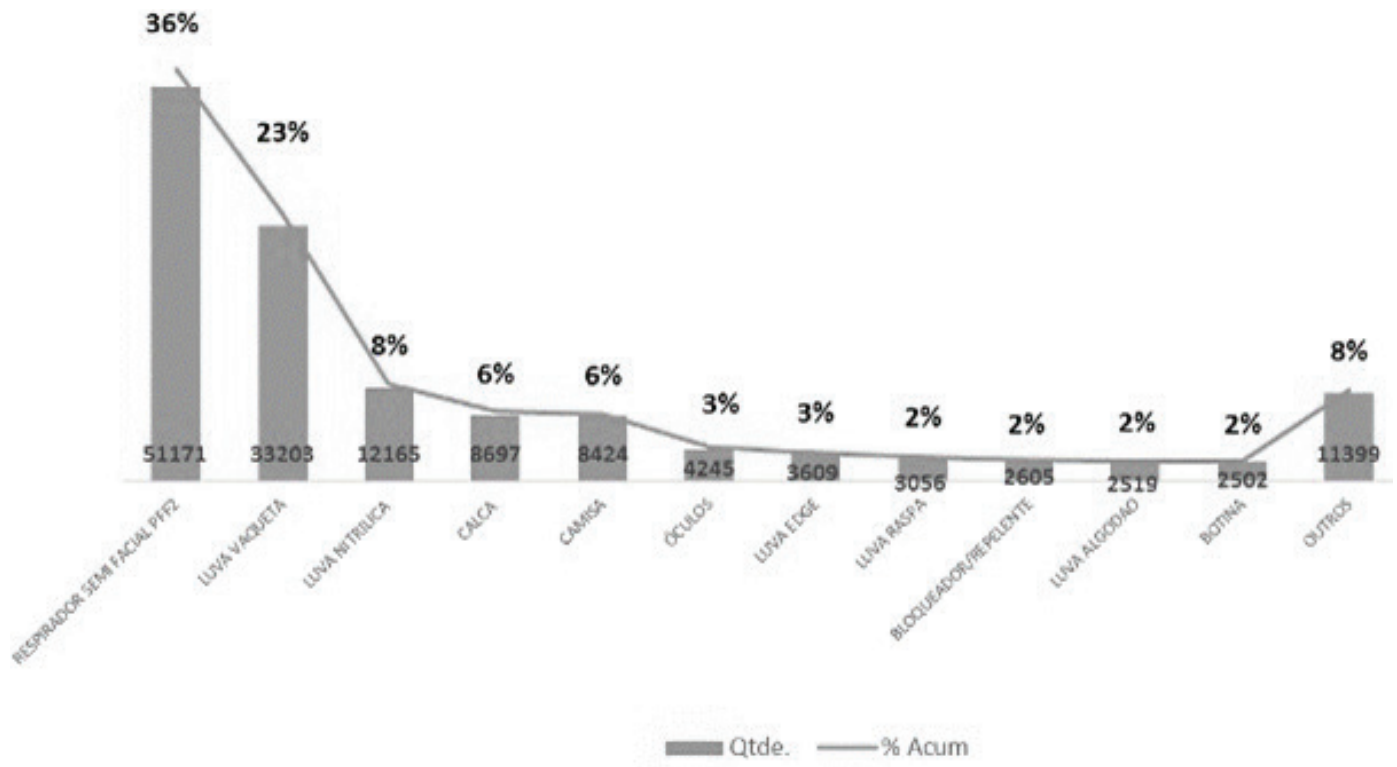

Figura 11 - SIGEPI: Maiores consumos de EPI no ano de 2017 (quantidade).

Desde o ano de 2014, a área de Segurança do Trabalho, com as áreas operacionais do TMPM, percebeu a necessidade de um estudo para dimensionamento de EPI nas várias atividades realizadas, e do mesmo modo, a oportunidade de melhorar o conforto dos empregados no uso dos EPIs, garantindo o mesmo nível de segurança. Para tanto, foi criado o 
programa EPI Inteligente para simplificar o uso de EPI, melhorando o conforto e o bem-estar dos empregados, sem comprometer sua saúde e segurança. No ano de 2017, foram realizadas e registradas cerca de 140 mil entregas de EPIs pelo sistema no TMPM.

\section{IMPLANTAÇÃO DO EPI INTELIGENTE}

O projeto de implantação do EPI Inteligente se deu em duas fases. Primeiramente, foi analisada a exposição aos riscos ao qual o empregado estava exposto em suas atividades. Inicialmente, o projeto foi aplicado considerando apenas as tarefas mais críticas. A avaliação foi realizada por meio de inspeção local por representantes do SESMT em parceria com as áreas. Durante o estudo, foram consideradas:

- As condições ambientais dos locais de trabalho ou circulação;

- As avaliações qualitativas e quantitativas de agentes ocupacionais;

- Os Quase Acidentes registrados;

- Histórico de acidentes pessoais;

- Conhecimento dos empregados;

- Particularidades de cada processo/tarefa.

Além da redução dos EPIs utilizados pela eliminação dos excessos e acessórios que não traziam resultados comprovados, foram introduzidos EPIs inovadores que garantiram maior conforto dos empregados na realização de suas atividades.

Os estudos dessas atividades foram feitos pela equipe de Segurança do Trabalho, por meio de relatórios técnicos que analisavam cada etapa da atividade e, como resultado, foram eliminados EPIs considerados ineficazes ou desnecessários para o gerenciamento do risco a serem substituídos por EPIs com maior eficácia e conforto.

As divulgações foram feitas por meio de boletins informativos, enviados por e-mail pela Gerência de Segurança do Trabalho para todas as áreas operacionais e administrativas. Por fim, cada área do TMPM foi identificada com o "selo" do Programa EPI Inteligente.

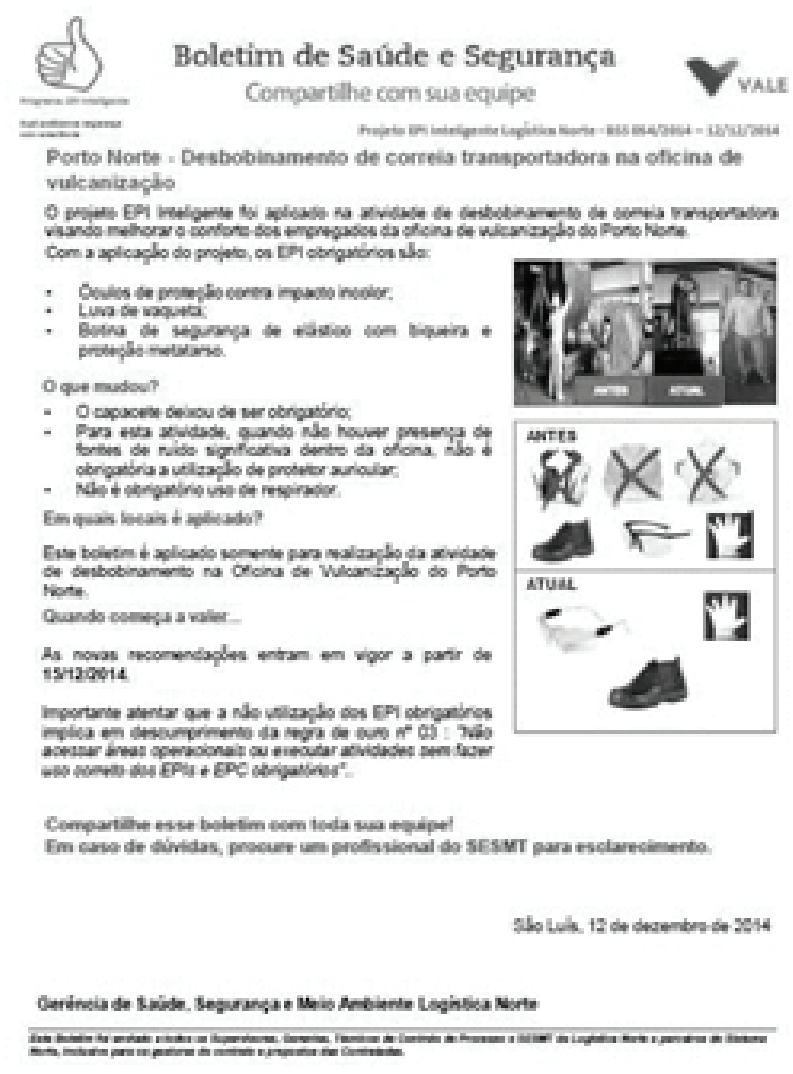

Figura 12 - Boletim informativo de divulgação e selo do programa EPI Inteligente. 


\section{a) Sinalização}

Na segunda fase, a partir da graduação dos riscos e tendo os cenários identificados nas análises: BAIXO, MÉDIO, ALTO e MUITO ALTO, as áreas foram sinalizadas verticalmente com placas que identificam os EPIs obrigatórios para o acesso de pessoas. As placas foram identificadas por cores a fim de facilitar a associação do risco ao local de trabalho, como: Riscos Baixo- Verde; Risco Médio- amarelo; Risco Alto e Muito Alto- vermelho.

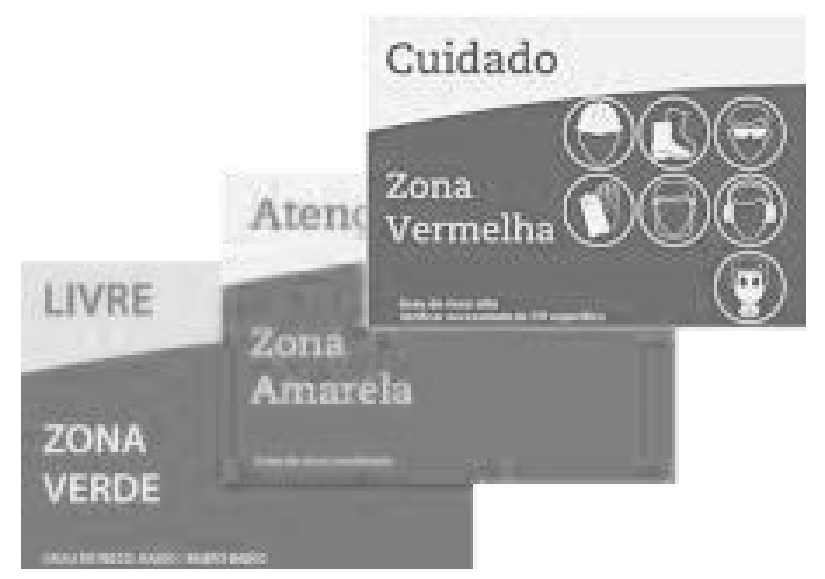

Figura 13 - Modelos de placa de sinalização vertical de EPI.

Em resumo, a metodologia do Programa EPI Inteligente consistiu em:

- Avaliar os riscos da área e entregar a matriz de aplicabilidade de EPIs necessários comparando os cenários antes e depois da análise;

- Tratar da sinalização conforme grau de exposição ao risco e os equipamentos de proteção necessários ao trabalhador;

- Estudar a possibilidade de substituição de um EPI por outro mais confortável, eficaz ou de menor custo, sem abrir mão da saúde e segurança.

\section{b) Ações preventivas/corretivas}

No início da operacionalização dos Postos de EPI Express, a demanda diária de entrega de EPIs aumentou. Diante disso, houve problemas em garantir os estoques nos níveis adequados. Em função dessa anomalia, criou-se a rotina de emissão de relatórios diários de itens de reposição para abastecimento e controle desses Postos, principalmente dos itens com maior rotatividade.

Com essa nova demanda, cada Posto de Entrega passou a gerir o controle dos níveis de estoque, e a aplicação da metodologia Kanban auxiliou nesse processo, com níveis de estoque (mínimo/máximo) identificados por cores, o que garante a rápida identificação da necessidade dos itens de reposição e redução do tempo de atendimento das requisições solicitadas.

Outro ponto importante foi o treinamento dos Entregadores dos Postos, pois o novo sistema eletrônico SIGEPI exigiu capacitações específicas nas funcionalidades e na operacio- 
nalização. Isso foi sanado com constantes capacitações do Normativo do SIGEPI junto aos envolvidos com o sistema, nos diversos níveis e perfis de atuação.

\section{c) Participação do trabalhador}

A implementação de todas as fases do projeto de EPI Inteligente contou com a participação efetiva dos empregados envolvidos nas atividades analisadas, em que, a partir do mapeamento das atividades de maior criticidade, foram realizados entrevistas e testes para a substituição dos EPIs com maior conforto, junto aos empregados, que, com a avaliação técnica do SESMT, validaram as substituições.

A liderança direta esteve envolvida no acompanhamento dos estudos das atividades das áreas, validações das análises e relatórios técnicos com a equipe de segurança do trabalho e divulgação dos resultados, por meio dos boletins informativos.

\section{d) Atendimento à legislação}

A implantação do controle eletrônico de fornecimento de EPI (SIGEPI), permitiu melhor gestão no que tange ao atendimento da NR6 - Equipamento de Proteção Individual - EPI, Portaria no. 3.214/78- MTPS, no que tange aos itens de Responsabilidade do empregador e dos empregados, quanto ao controle de registro de entregas, EPI adequado ao risco, exigência do uso quanto às periodicidades de trocas, registro do fornecimento quanto às fichas de EPI eletrônicas e rastreabilidade das mesmas, em função do sistema armazenar um banco de dados com o histórico do empregado, por até 20 anos.

A atualização da base de dados do SIGEPI também garante que todos os EPIs utilizados pelo empregado são homologados pela Vale, por meio da área de Suprimentos, onde há a garantia de que o EPI, de fabricação nacional ou importado, só pode ser comercializado com a indicação do Certificado de Aprovação - CA, expedido pelo órgão nacional de segurança no trabalho do Ministério do Trabalho e Emprego (206.0001-9/I3).

\section{Resultados}

A implementação do sistema informatizado de gestão de EPI e o projeto de EPI Inteligente trouxeram como benefícios para o Terminal Marítimo Ponta da Madeira:

- Simplificação de EPI nas atividades (EPI Inteligente), com 48 Boletins de EPI Inteligente divulgados no Terminal Marítimo Ponta da Madeira, conforme mapeamento das atividades mais críticas;

- Mapeamento e sinalização das áreas;

- Busca de EPI inovadores, com menor custo e maior qualidade (EPI Inteligente);

- Definição de EPI por função (SIGEPI);

- Controle eletrônico de fornecimento de EPI (SIGEPI);

- Processo inovador que soluciona a fragilidade nas informações atuais frente ao processo legal trabalhista;

- Compartilhamento de EPI e práticas adotadas nos Portos. 


\section{Aplicaçōes do Projeto EPI Inteligente}

\begin{tabular}{|c|c|}
\hline & 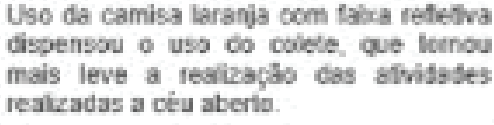 \\
\hline & 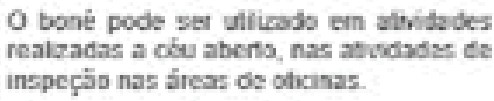 \\
\hline & $\begin{array}{l}\text { Pemidido o uso da camisa manja curta } \\
\text { nas alividades de inspeção. }\end{array}$ \\
\hline & $\begin{array}{l}\text { Penmidido o usa de bermuda nes } \\
\text { alimidades de operagōes nátubras. }\end{array}$ \\
\hline & $\begin{array}{l}\text { E posshal o uso ds teris ou calcases } \\
\text { fechedos que cubrem o dorso do pe abs } \\
\text { aress administretwes. }\end{array}$ \\
\hline
\end{tabular}

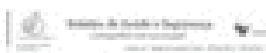

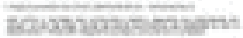

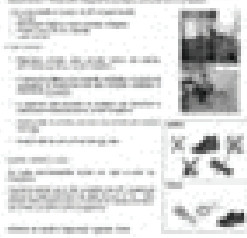

Doletina Informative

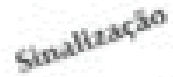

Culdaso

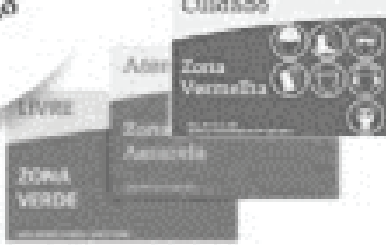

Figura 14 - Projeto EPI Inteligente exemplos de resultados da aplicação do projeto.

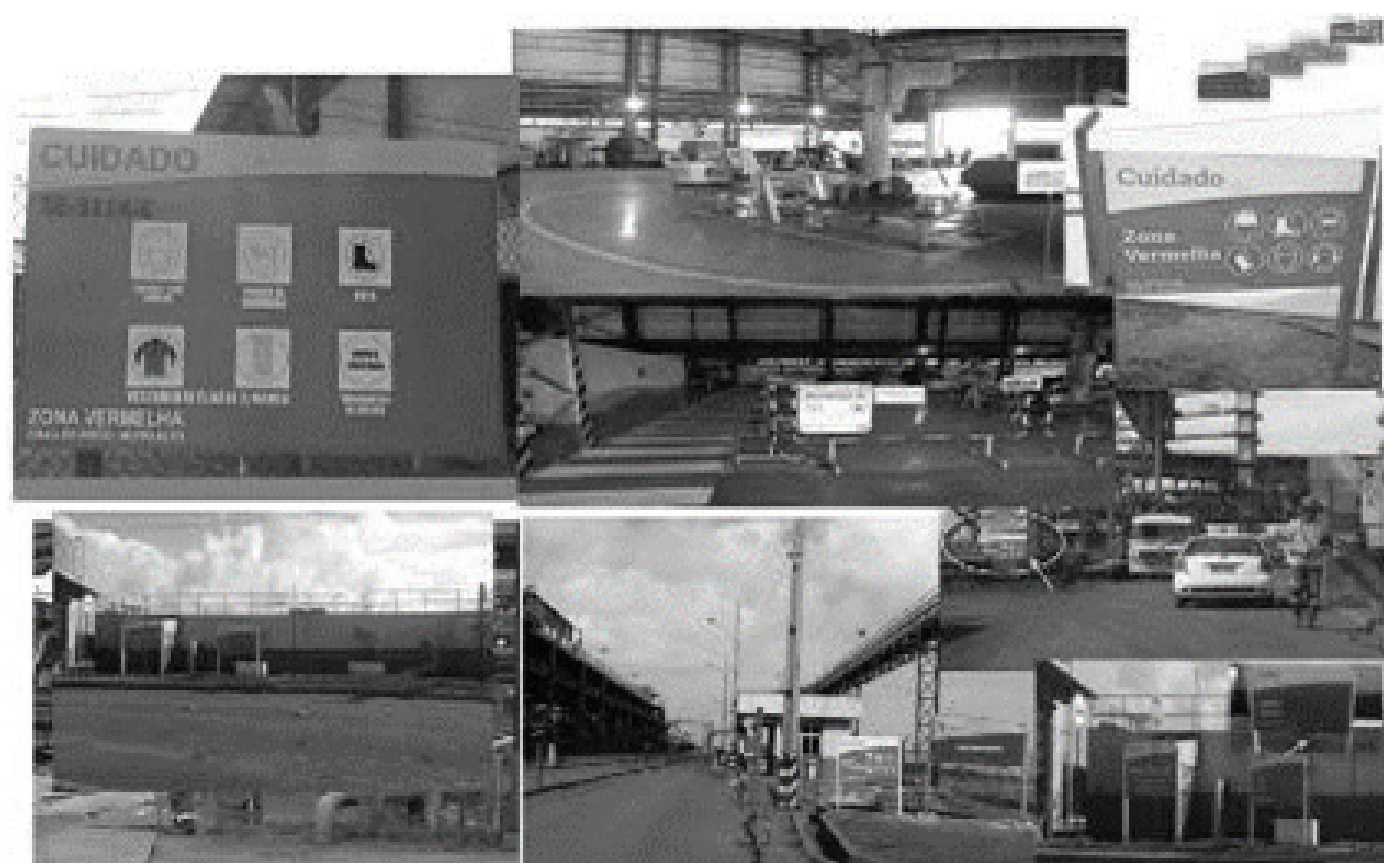

Figura 15 - Sinalização vertical de EPI, conforme riscos associados no Terminal Marítimo Ponta da Madeira. 


\section{CONSIDERAÇÕES FINAIS}

São recebidos com frequência processos jurídicos relacionados ao fornecimento de EPI. Com a implantação do SIGEPI no TMPM, tem-se a oportunidade de melhorar a gestão e controle com o armazenamento do histórico e da rastreabilidade das informações do sistema, por meio da ficha individual de EPI do empregado.

A criação dos Postos de Entrega de EPI Express nas áreas operacionais do Porto proporcionou maior agilidade na aquisição dos EPIs de maior uso, além de reduzir o tempo de espera do empregado no registro e recebimento do seu EPI, por meio da senha individual ou leitura biométrica.

A implantação do sistema automatizado tornou o processo mais confiável, porém ainda existem oportunidades no controle dos relatórios de consumo de EPI por função e em relação aos EPI atualmente utilizados considerando a qualidade, conforto e preço.

A implantação do Projeto EPI Inteligente proporcionou maior conforto aos empregados, com a eliminação de excessos e utilização do que realmente é necessário para a execução com segurança das atividades. Soma-se a isso a maior aproximação da equipe de segurança do trabalho com as áreas operacionais, onde o profissional de segurança geralmente é visto como "fiscal". Além do conhecimento técnico agregado com todas as partes envolvidas.

Ainda se vê oportunidades na busca por inovações para os equipamentos de proteção individual e se entende que isso é um trabalho da equipe de segurança do trabalho com as áreas operacionais, na busca de parcerias e desenvolvimento com os fornecedores.

\begin{tabular}{|l|l|}
\hline EPI Inteligente \\
Simplificaçăo de EPI visando conforto e bem-estar sem comprometer a \\
saude e segurança dos colaboradores. \\
Cerca de 48 projetos implantados desde 2014 e sinalizaçăo das áreas.
\end{tabular}

Figura 16 - Quadro resumo dos benefícios da gestão de EPI com os programas implementados. 
Em suma, a oportunidade de compartilhamento das melhores práticas adotadas possibilitou o levantamento das principais questões junto ao corporativo Vale e foi despertado o foco em simplificação, padronização e redução de custos.

\section{ReFERÊNCIAS}

VALE, S.A. Nossa história. Rio de Janeiro: Brasil Editora, 2013. . 30 anos do Terminal Marítimo Ponta da Madeira. São Luís: Vale, 2016. . Book de resultados de SSMA Logística Norte 2017. São Luís: Vale, 2018.

. Norma Regulamentadora No 06 (NR 06). Equipamento de Proteção Individual EPI, Portaria no. 3.214/78 - MTPS.

. Norma Regulamentadora Nº9 (NR 09). Programa de Prevenção de Riscos Ambientais - PPRA, Portaria n ${ }^{\circ}$. 3.214/78 - MTPS.

Kanban. Disponível em: https://www.significados.com.br/kanban/> Acesso em 2 de abril de 2018.

Submetido em: 6-9-2018

Aceito em: 7-11-2018 